\title{
Legal regulation of artificial intelligence in the financial services market: a comparative analysis
}

\author{
Olga Viktorovna Sushkova ${ }^{1}$ and Aleksey Vladimirovich Minbaleev \\ Kutafin Moscow State Law University, Department of Information law and Digital Technologies, \\ Moscow, Russia
}

\begin{abstract}
The study aims to conduct a comparative analysis of the legal regulation of the use of artificial intelligence in the financial services market. The research was carried out based on empirical methods of comparison, description, interpretation, and theoretical methods of formal and dialectical logic. Particular scientific methods were used: legal-dogmatic and the method of interpreting legal norms. The financial services market is currently expanding access to finance. At the same time, the normative legal regulation of artificial intelligence technology (hereinafter referred to as AI) in the financial sector is rather fragmentary and declarative. The position is expressed that artificial intelligence in the financial services market can lead to systemic risks and the manipulation of such a market on trading platforms. It is argued that the development of artificial intelligence should adhere to regulatory goals related to market security, consumer protection, and market integrity. The authors highlight regulatory objectives and possible regulatory methods for peer-to-peer platforms that ensure equality and fair access to financial instruments. The results of the work were the justification for the need to use robotic consultants in the field of investment activities to provide consumers with access to financial services markets. It is shown that the current legal regime does not provide adequate protection for consumers of financial services in this regard. At the same time, the authors believe that artificial intelligence can be used as a form of RegTech (regulatory technology) to optimize compliance processes, thereby increasing competition in financial markets and benefiting consumers. However, such use may be contrary to the principles of confidentiality, data protection, and ethical considerations. The novelty of the work lies in the proposed basic guidelines for the development of detailed regulators for the certification of algorithms and digital platforms, for enhancing ex-ante and ex-post protection of individuals using robotic consultants, and for addressing the question of how individual rights such as privacy rights and data rights can be exercised.
\end{abstract}

Keywords: artificial intelligence, capital markets, investment activities, information and communication technologies

\footnotetext{
${ }^{1}$ Corresponding author: ovsushkova@mail.ru
} 


\section{Introduction}

As we enter the fourth industrial revolution, AI technologies simulate business process automation as much as possible. At the same time, various algorithms for automatic trading can lead to failures in both the commodity and the stock market. The introduction of AI technology into the business arena is viewed by many as a factor in improving the economic situation, followed by increased production and increased jobs. On the one hand, there is a reduction in production costs and time, an increase in production processes, safety, and quality. On the other hand, business automation through the use of AI can lead to economic stagnation [1].

It is rightly noted in the Concept for the development of regulation of relations in the field of artificial intelligence and robotics technologies until 2024 [2] that the lack of an unambiguous understanding of the content of the "artificial intelligence", "robot", "smart robot", "robotics", "intelligent agent" terms leads to terminological problems in the formation of regulation.

At the same time, in various fields, it may be necessary to formulate different definitions depending on the industry of application of artificial intelligence and robotics technologies [3]. For this reason, during the period considered in the Concept, it is proposed to avoid the introduction of a unified for all industries normative definition of these terms to the legislation of Russia.

It is fairly noted by Professor Andreev [4] that Sinyukov believes that "in digital law, classical law is reduced to a minimum, in fact, to signs of recognition and efficiency (ethics). In this sense, digital law is a combination of non-legal regulators, which, in certain combinations, provide legal quality" [5]. Minbaleev considers digital legal relations as relations on the use of data in digital form regulated by law, as well as the results of data analysis and the results of processing and use of such data in various spheres of public life using digital technologies [6]. The structure of digital legal relations is determined by a set of digital relations, subjects of digital relations, and their content is determined by a set of rights and obligations of subjects of digital relations. In this regard, it is important to understand the specifics of digital relations in connection with the use of AI in the financial services market.

\section{Methods}

The method of system analysis and content was primarily used in carrying out the research, as well as such private scientific methods as the comparative-legal method and the method of legal modeling. All of them make it possible to effectively ensure the implementation of the research goal - to identify the features of the legal regulation of artificial intelligence in the financial services market in various legal orders by identifying the features of this mechanism and the means utilized.

Access to finance requires a regulatory framework to protect investors using advisor robots for personal or commercial finance. In this regard, it is important to study the possibilities of using the current legislation without changing it, as well as the prospects for making certain changes, using the method of system analysis and content analysis. The comparative legal method was used in the analysis of the Great Britain legislation, where investors are protected by common law, statutory law, and regulatory rules. Under common law, investors are protected by contract law, by the duty of care under tort law and the provisions of the fiduciary duty, and under the law of justice. In contract law, investors are protected by the terms of the contract as well as various principles, including error, 
misrepresentation, coercion, undue influence, and legality. AI technologies can be used to detect actions that violate the integrity of the market, such as market manipulation, including pricing, disinformation, insider trading, and money laundering. In addition, such AI technologies can be used by financial institutions, regulators, politicians, or even private market watchers to detect and prevent such misconduct. When such AI technologies are used for this purpose, they are referred to as "regulatory technologies" (RegTech) [7]. RegTech will also include SupTech, which is mainly used for market surveillance purposes [8]. When RegTech is used to identify market illegal action, it includes elements of market surveillance, including the collection of individual data. The main goal of RegTech is to protect the integrity of the market.AI is used by exchanges as a SupTech service, as well as to provide supervision. It is used by financial institutions as a RegTech service [9]. In addition to providing the previously mentioned suitable development regimes for investor protection, another emerging challenge is the need for data governance that protects privacy and data [10].

\section{$3 \quad$ Results}

Analysis of the literature indicates that there is no consensus on the definition of the gap in financial advice [11]. As defined in the Financial Advisory Market Review (FAMR), financial advice gaps refer to "situations in which consumers cannot receive advice and guidance on pricing in the financial services market and on the price of a particular service they are willing to pay" [12]. Cost is not the only factor showing this gap. Thus, the legal gap in the definition and implementation of financial advice provided in digital financial markets should be defined as "the difference between the number of people who currently seek advice and those who would seek advice if there was a cheaper and less intensive process" [12]. There is a widespread perception that there is a gap for (potential) clients who have lower income or lower asset levels and who either cannot afford consulting fees or find it difficult to access. The FAMR concludes that the main reason for the gaps in financial advice is that there are not enough financial advisors because there are too many advisors serving wealthy clients. An increasing number of clients are finding themselves in a financial advisory deficit, according to a survey by OpenMoney and YouGov.

The role of robotic consultants like Nutmeg and Wealthify is to fill this gap in financial consulting. Robotic consultants are a type of financial advisor that provides financial advice "in person" or allows managing investments online with moderate or minimal human intervention. "Robotic consulting" is a general term that refers to a wide range of automated online tools and algorithms for identifying financial or investment decisions for an individual portfolio. This process is based on financial analysis algorithms based on mathematical rules. Thus, through economic modeling, AI is the cornerstone of this technology.

These algorithms are performed by implementing a computer program in such a way that, in extreme cases, human intervention is not required, but it is possible to provide the client with real-time access to information [13]. Consequently, robotic consultants can improve access to finance and reduce the cost of financial access, leading to more affordable financial services.

\section{Discussion}

Great Britain is looking at financial technology as an effective tool to tackle the problem of financial isolation, as well as a way to encourage companies to develop innovative 
processes and thus increase consumer access to financial services for businesses and investors. Compared to bank savings, p2p (peer-to-peer) platforms offer higher interest rates. In addition, investments through $\mathrm{p} 2 \mathrm{p}$ platforms offer higher liquidity than traditional real estate investments [14].

Most importantly, $\mathrm{p} 2 \mathrm{p}$ platforms usually split the capital into several parts for several borrowers, thereby reducing the risk of large losses. Algorithmic trading can be used on $\mathrm{p} 2 \mathrm{p}$ platforms to expand access to finance. Essentially, algorithmic trading is simply the use of specialized software to implement predefined decision rules to assess market conditions and other data for making trading decisions without human intervention.

Tarasenko [15] notes that the banking industry requires a high degree of security and that there is a potential opportunity to minimize or eliminate the risk of fraud in it by using decentralized blockchain technology. For example, the financial conglomerate ING, whose bank is the world leader in terms of customer base, has found the perfect balance between security and privacy using blockchain technology. This is achieved by embedding such a component as a "digital notary" into the platform, the functions of which include approving or rejecting a transaction with a "zero level of knowledge". This can be applied to payments on securities, bonds, letters of credit, bank guarantees, escrow accounts, that is, in cases where there is mistrust between the parties and it is necessary to reduce the time and financial costs of conducting transactions [15].

\section{Conclusion}

The objectives and methods of regulation related to management systems and processes in the field of securities trading and investment services in which AI is applied were considered. The authors use HFT as an example to study how AI is regulated in a non-consumer trading platform. The main goal of regulation is to combat systemic risks sudden disruptions, liquidity risks, and procyclical behavior. The secondary goal is to protect investors from market manipulation (fairness). The main regulatory approach is to require operators - HFT specialist firms, securities firms, private traders, and trading floors - to have internal risk management systems and processes. Thus, these operators are also required to consider the safety and integrity of the market.

Instead of traditional investment services, consumers can use online robot advisors to purchase financial products that may not be available to them because they do not have access to the information provided by asset management advisors. Thanks to open data and the development of more sophisticated algorithms, users can choose online consultants who provide more economic services for consulting and investment portfolio management. Consumers need to be protected from poorly designed algorithms that do not act in their best interests, discriminate against them, or harm them through errors.

\section{References}

1. J.D. Sachs, L.J. Kotlikoff, Smart machines and long-term misery. NBER Working Paper, 18629 (2013)

2. Order of the Government of the Russian Federation of August 19, 2020 No. 2129-r "On approval of the Concept for the development of regulation of relations in the field of artificial intelligence and robotic technologies until 2024". Collected Legislation of the Russian Federation, 35, Art. 5593 (2020) 
3. K.Y. Nikolskaya, S.A. Ivanov, V.A. Golodov, A.V. Minbaleev, G.D. Asyaev, Review of modern DDoS-attacks, methods, and means of counteraction, in 2017 International Conference "Quality Management, Transport, and Information Security, Information Technologies” (IT\&QM\&IS), 87-89 (Saint Petersburg, 2017). https://doi.org/10.1109/ITMQIS.2017.8085769

4. V.K. Andreev, Journal of Russian Law, 3, 58-68 (2020). https://doi.org/10.12737/jrl.2020.030

5. V.N. Sinyukov, The concept and significance of digital law in the modern legal system, in V.V. Blazheeva, M.A. Egorova (eds.), Digital Law: textbook, 19 (Moscow, 2020). https://doi.org/10.31085/9785392227297-2020-640

6. V.V. Blazheeva, M.A. Egorova (eds.), Digital Law: textbook, 67 (Moscow, 2020). https://doi.org/10.31085/9785392227297-2020-640

7. RegTech applies to new technologies developed to help overcome regulatory challenges in financial services, FCA, RegTech (2017) https://www.fca.org.uk/firms/innovation/regtech

8. P. Armstrong, Developments in RegTech and SubTech (2018). Accessed on: June 30, 2021. [Online]. Available:

https://www.esma.europa.eu/sites/default/files/library/esma71-99-1070_speech_on_reg tech.pdf

9. Big data, artificial intelligence, machine learning and data protection, Information Commissioner's Office (2017). Accessed on: June 30, 2021. [Online]. Available: https://ico.org.uk/media/for-organisations/documents/2013559/big-data-ai-ml-and-data -protection.pdf

10. O.V. Sushkova The Impact of Digital Technologies on the Development of Self-Regulation, in 2nd International Scientific and Practical Conference on Digital Economy (ISCDE 2020), Advances in Economics, Business and Management Research, 156, 630-635. https://doi.org/10.2991/aebmr.k.201205.107

11. K. Petrie. Informed decision-making: an evaluation of the advice gap (2017). Accessed on: June 30, 2021. [Online]. Available: https://www.smf.co.uk/wp-content/uploads/2017/06/5599-SMF-Financial-Advice-GapReport-WEB.pdf

12. H.M. Treasury. Financial advice market review. Final report. FCA (2016). Accessed on: June 30, 2021. [Online]. Available: https://www.fca.org.uk/publication/corporate/famr-final-report.pdf

13. Empirica, Reasons for asset managers to implement robo adviser software (2016). Accessed on: June 30, 2021. [Online]. Available:

https://empirica-software.com/reasons-for-asset-managers-to-implement-robo-adviser-s oftware

14. Y. Murciano. P2P lending offers an attractive entry point into property investment, Mortgage Introducer (2019). Accessed on: June 30, 2021. [Online]. Available: https://www.mortgageintroducer.com/p2p-lending-offers-attractive-entry-point-propert y-investment/

15. O.A. Tarasenko, Digital transformation of foreign banking systems, in V.A. Laptev, O.A. Tarasenko (eds.), Digital economy: the conceptual basic legal regulation of business in Russia (Prospect, Moscow, 2020). https://doi.org/10.31085/9785392328604-2020-488 